\title{
TANDA BUDAYA DALAM CERPEN FILOSOFI KOPI KARYA DEE LESTARI TINJAUAN SEMIOTIKA BUDAYA JURIJ LOTMAN
}

\author{
Jalu Norva Illa Putra \\ Universitas PGRI Yogyakarta \\ jalunorva@gmail.com
}

\begin{abstract}
Abstrak: Tulisan ini mengambil objek sebuah cerpen dari Dee Lestari yang berjudul Filosofi Kopi. Cerpen ini bertemakan tentang kopi, dan gambaran bagaimana kopi memiliki karakter dan akan mewakili orang meminumnya. Selanjutnya dari pemaknaan yang muncul atas berbagai jenis kopi akan dilihat budaya yang melatarbelakangi pemaknaan tersebut, bagaimana makna tersebut bisa diterima dalam sebuah lingkungan hingga pada akhirnya menuju tentang bagaimana penggambaran simbolisasinya di dalam cerpen serta relevansi yang ada terkait dengan fakta masa kini. Cerpen ini akan dilihat melalui teori semiotika budaya Jurij Lotman. Cerpen ini mengandung beberapa oposisi yang dapat dikontestasikan yaitu kopi yang mewakili bentuk budaya tradisional dan modern. Hal tersebut juga didukung setting yang memberikan penggambaran budaya yang sama juga. Selanjutnya wacana barat dan timur juga dikontestasikan melalui berbagai jenis kopi yang ada, hingga penggambaran kapitalisme yang berakhir dengan kekalahan serta kontestasi antara tradisional dan modern yang juga dimenangkan oleh budaya tradisional. Selanjutnya cerpen ini dipergunakan sebagai sebuah alat pemberdaya kapitalisme
\end{abstract}

Kata kunci: semiotika budaya, semiosphere, filosofi kopi, tanda budaya

\section{CULTURE SIGNS IN THE SHORT STORY OF FILOSOFI KOPI BY DEE LESTARI: A STUDY OF CULTURAL SEMIOTICS BY JURIJ LOTMAN}

\begin{abstract}
This article takes the object of a short story from Dee Lestari entitled Filosofi Kopi. This short story is about coffee, and an illustration of how coffee has character and will represent people drinking it. Furthermore, culture will be seen which lies behind the meaning of each type of coffee, how that meaning can be accepted in an environment until finally leading to how its symbolic depiction in the short story and the relevance that exists is related to the facts of the present. This short story will be seen through Jurij Lotman's semiotic culture theory. This short story contains some opposition that can be contested, namely coffee which represents traditional and modern forms of culture. It is also supported by settings that provide the same cultural depiction. Furthermore, western and eastern discourses are also contested through various types of coffee that exist, until the depiction of capitalism which ends with defeat and contestation between traditional and modern which is also won by traditional culture. Furthermore, this short story is used as a tool to empower capitalism
\end{abstract}

Keywords: cultural semiotics, semiosphere, Filosofi Kopi, cultural signs 


\section{PENDAHULUAN}

Sastra adalah produk dari sebuah bahasa yang di dalamnya tercetak pula sebuah ranah kebahasaan yang akan membentuk sebuah makna. Sehingga sastra tidak akan pernah bisa lepas dari konteksnya - konteks dalam karya sastra dan konteks di luar karya sastranya. Tulisan ini akan mengambil sebuah cerpen sebagai sebuah objek kajian. Cerpen tersebut ditulis oleh Dee Lestari dengan judul Filosofi Kopi. Secara singkat Filosofi Kopi merupakan sebuah cerpen yang menceritakan tentang dua orang sahabat yang memiliki sebuah kafe. Mereke membangun kafe tersebut dengan sebuah ideologi bahwa kopi yang mereka buat haruslah memiliki sebuah makna.

Hal yang menjadi titik tumpu dalam tulisan ini adalah perihal pemaknaan. Kopi menjadi simbolisasisimbolisasi yang memiliki makna. Makna ini tidak hanya satu, kopi menjadi mendua ketika dihadapkan dengan konteks budaya yang melingkupi kopi tersebut.

Cerpen ini akan dilihat dalam sebuah sudut pandang semiotika kontemporer. Cerpen ini dianggap sebagai sebuah tanda akan adanya budaya tertentu. Budaya seperti apa dan bagaimana bentuk tandanya adalah hal yang tengah dicari dalam tulisan ini.

Kembali lagi pada paparan sebelumnya tentang konteks, cerpen ini akan dilihat dengan konteks ke dalam karya sastra dan ke luar karya sastra. Maksudnya, karya ini akan dilihat dalam konteks unsur yang ada dalam cerpen tersebut, terkait kata, kalimat, serta gambaran yang ada dalam cerpen. Selain hal tersebut akan dilihat juga sisi luarnya, bagaimana cerpen ini terkait dengan hal-hal yang berada di luar karya atau cerpen itu sendiri.

Selanjutnya akan dipergunakan sebuah teori untuk membantu menjawab pertanyaan diatas. Teori yang dipergunakan adalah teori semiotika milik Jurij Lotman. Lotman memeparkan tentang apa itu semiotika Budaya. Semiotika dengan mengadopsi pandangan budaya tertentu. Bahawa dalam sebuah karya sastra memiliki tanda-tanda budaya tertentu.

\section{LANDASAN TEORI}

Yuri Lotman

(1977:9)

memandang seni (sastra) sebagai secondary modeling system dan dibangun di atas model bahasa (secondary modelling system, like all semiotic system, are constructed on model of language). Lotman beranggapan bahwa sastra juga memiliki pola "bahasa" sendiri seperti halnya keilmuan lain. Terlebih lagi sastra memiliki kecenderungan menggunakan medium utamanya berupa bahasa. Hal inilah yang akan menjadi model untuk melihat tataran semiotik yang muncul. Pandangan Lotman ini juga ditegaskan dalam Handbook of Semiotics yang ditulis oleh Noth (1990:309). Semiotik adalah ilmu yang mengkaji tanda dalam kehidupan manusia. Artinya, semua yang hadir dalam kehidupan kita dilihat sebagai tanda, yakni sesuatu yang harus kita beri makna (Hoed, 2011: 3).

Menurut Lotman (1990:16), in the history of art this is especially common, since every innovatory work of art is sui genaris a work in a language that is unknowon to the audience and which has to be reconstructed and mastered by its addressees, di dalam sejarah seni telah 
diketahui secara umum, bahwa setiap karya seni terobosan merupakan hal yang unik dan berharga dalam bahasa yang dikenal oleh audiensinya dan harus direkonstruksi dan direka ulang oleh addressee-nya. Hal yang dikatakan Lotman ini secara sederhana seperti yang dikatakan faruk terkait tentang hubungan tanda dengan makna yaitu mimetik dan ikonik. Kedua hal ini memiliki konteks yang akan menuju kepada suatu pemaknaan tertentu yang boleh jadi hanya dapat dimengerti oleh para pemilik konteks tersebut.

Tugas utama penelitian semiotik menurut Lotman adalah to find a series of thinking object, compare them, and to deduce the invariant feature of intelligence (1990:2). diartikan sebagai usaha untuk menemukan rangkaianrangkaian pemikiran tentang obyek, membandingkan di antaranya kemudian menarik kesimpulan variasivariasi yang ada.

Bagi Lotman, sastra adalah secondary modelling system. Sastra menjadikan bahasa natural sebagai bahasa yang baru. Bahasa yang baru ini menempati posisi secondary. Dalam konteks ini, bahasa sastra dan bahasa sehari-hari menjadi dua hal yang akan bermakna berbeda

Diagram sederhana ini (Siegers (diterjemahkan oleh Suminto), 2000: 15) sedikit dimodifikasi dari milik Jakobson. Dalam konteks tulisan ini atau mungkin secara lebih spesifik pada bahasan sastra, addresser akan diidentifikasi menjadi karya sastra itu sendiri atau penulisnya, atau yang lebih spesifik dapat juga sebagai tokoh yang ada dalam karya. Sedangkan addresse akan identik dengan pembaca atau orang yang akan memaknai. Message diartikan seperti halnya walaupun dalam satu sistem bahasa yang sama.

Dalam tataran secondary ini apa yang seringkali disebut tentang otomatisasi menjadi tidak mutlak. Dapat diibaratkan kursi tidak bermakna sebagai sebuat tempat duduk, melainkan sebagai hal yang lain , sebuat temoat, atau kekuasan atau hal lain yang dirujuk dalam konteks budaya tertentu. Pembaca tidak akan menuju pemkanaan kursi yang sesungguhnya ketika membaca sebuah karya, makna yang muncul langsung tertuju kepada makna kedua (secondary) karena bekal budaya yang dimiliki oleh pembaca. Hal ini juga dapat disebut sebagai defamiliarisasi, yang pertama kali disebut oleh Victor Shklovsky (Selden, 1996: 5). sebuah proses untuk menjadikan tidak familiarnya suatu bahasa.

Dalam buku Rien T. Sergers yang telah diterjemahkan oleh Suminto A. Sayuti dengan judul Evaluasi Teks Sastra (2000: 15) terdapat satu sub judul yang bisa jadi menjadi hal yang cukup mendasar yaitu tentang proses komunikasi sastra. Hal ini terkait dengan yang dikatakan Lotman tentang "secondary system".

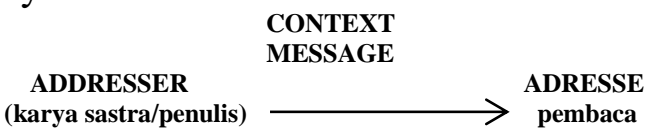

makna yang ingin disampakan, Lotman sendiri juga mengartikan message sebagai a massage. Lotman juga mengungkapkan satu hal lagi yaitu a model, yang diartikan adalah konteks keseluruan yang melingkupi diagram ini, yaitu bahasa dalam konteks yang abstrak, bahasa sebagai bahasa itu sendiri.

\section{Struktur teks naratif}

$$
\text { Lotman dalam Faruk }
$$

(2002:27). membagi struktur teks 
naratif menjadi tiga bagian. Ruang artistik terbangun dari beberapa medan semantis yang berupa elemen-elemen yang saling berhubungan satu sama lain dalam bentuk oposisi berpasangan, baik secara vertikal maupun horizontal. Plot adalah serangkaian peristiwa yang saling berhubungan satu sama lain dalam kerangka usaha penerobosan terhadap medan-medan semantik yang membangun struktur ruang artistik di atas. Persona adalah representasi fungsi-fungsi abstrak, baik fungsi agen yang menjadi penerobos medanmedan semantik, maupun perintang yang mencoba mempertahankannya.

\section{Semiosphere}

Budaya adalah teks yang sangat luas, dan teks dapat dimengerti sebagai rangkaian tanda-tanda. Oleh karena itu, diperlukan mekanisme semiotik paling sederhana, tetapi dapat mencakup keseluruhan teks tersebut (budaya), seluruh bahasa, seluruh sistem semiotik, yang selalu berada dalam proses perubahan yang konstan dan pada sebuah level yang mengandung kualitas-kualitas yang menyatu. Mekanisme tersebut dinamakan semiosphere, yaitu unit semiosis yang merupakan mekanisme fungsional yang paling kecil, bukanlah sesuatu yang terisolasi, melainkan seluruh ruang semiosis budaya yang (selalu) dipertanyakan. Berharap untuk selalu dipertanyakan, supaya komunikasi terus terakomodasi sesuai dengan zamannya untuk kelanjutan kehidupan. Inilah sistem semiotik Lotman, sebuah ruang yang dinamakan

Lotman membentuk sebuah sistem semiotik yang didalamnya mampu mencakup seluruh aspek dari semiotik, yaitu semiosphere. semiosphere; the unit of semiosis, the smallest functioning mechanism, is not the separated language but the whole semiotic space of the culture in question. This is the space we term the semiosphere. The semiosphere is the result and the condition for the development of culture; (Lotman 1990: 125).

Semiosphere adalah sebuah ruang semiotik yang diperlukan untuk berinteraksinya fungsi dan keberadaan bahasa dan sistem tanda lainnya. Ruang ini mampu melingkupi dan menjelaskan dari setiap interaksi yang ada.

Selanjutnya semiosphere ini dipandang sebagai sebuah teks budaya yang terstruktur sekaligus abstrak. Hal ini yang menjadikan sulit diprediksinya makna yang muncul. Konteks budaya sangat berpengaruh dalam proses pemaknaan dan di dalam semiosphere inilah konteks berada di dalam sekaligus melingkupinya. Dapat dicontohkan pemaknaan yang sangat terkait dengan mitos, agama, atau kepercayaan tertentu. Hal-hal yang bersifat umum akan sulit untuk memahami hal-hal yang diatur dan hasil dari bentuk-bentuk semiosphere tersebut. Atas dasar hal tersebut diperlukan merunut konstruksi yang ada dalam semiosphere tersebut dan selanjutnya merekonstruksi tanda yang muncul terkait dengan semiosphere yang ada.

Lebih jauh lagi demi mendapatkan pemaknaan yang relevan seringkali diperlukan perunitan tipologi budaya tertentu. Hal ini dimaksudkan untuk menemukan sistem yang mengatur entah secara umum atau secara khusus. Merekonstruksi kode budaya tidak berarti menjelaskan semua fenomena budaya itu, melainkan memungkinkan 
kita untuk memilih lalu kemudian menjelaskan mengapa ada budaya yang telah menghasilkan fenomenafenomena tersebut (Lotman, 1990: x).

Teks budaya adalah mekanisme yang mengangkat sebuah sistem ruang-ruang semiotik yang heterogen yang saling berelasi dan kemudian dislurkan. Dengan kata lain, sesuai dengan medium yang diciptakan Lotman, teks semiosphere adalah sebuah fenomena kebudayaan yang menonjol dalam sebuah rentang waktu tertentu atau dalam sebuah kebudayaan. Eco (dalam Lotman 1990: x) mengatakan

semiotic system are models which explain the world in which we live (point 4), all at once, reconstructioning the code of a culture does not mean explaining all the phenomena of that culture, but rather allows us to explain why that culture has produced those phenomena;

sistem semiotik adalah model-model yang menjelaskan dunia tempat kita hidup serta merekonstruksi kode suatu budaya. Namun tidak serta merta menjelaskan seluruh fenomena budaya itu melainkan untuk menjelaskan mengapa budaya itu menghasilkan fenomena tertentu.

\section{HASIL DAN PEMBAHASAN}

Tulisan ini akan membahas sebuah cerpen dari dewi Lestari atau sering dikenal dengan nama penanya yaitu Dee. Cerpen tersebut berjudul Filosofi Kopi dibuat pada tahun 1996 dan diterbitkan dalam kumpulan cerita dengan judul yang sama.

\section{Tanda Budaya di dalam Cerpen Filosofi Kopi}

Lotman (1977:14) berpendapat bahwa bahasa tidak hanya merupakan sistem komunikasi, tetapi juga sebuah sistem permodelan (modeling System), atau lebih dari itu, kedua fungsinya dihubungkan tanpa terpisah. Dengan menjadikan sastra sebagai model kehidupan (Eco dalam Lotman, 1990:x), maka Lotman meletakkan semiotika ini sebagai semiotika kebudayaan. Selanjutnya Lotman akan melihat dalam beberapa aspek seperti a message, a model, struktur naratif, dan semiosphere.

A message diartikan sebagai bentuk pesan atau informasi. Filosofi kopi sebagai sebuah karya sastra memiliki sisi pesan atau informasi. Bentuk pesan dapat dirujuk pada dua hal yaitu denotasi dan konotasi apabila meminjam istilah dari Hjelmslev atau surplus of meaning (makna tambah) apabila meminjam istilah Ricoeur. Berikut dapan dilihat dalam bagian kutipan berikut.

Seperti pilihan Anda ini, cappucino. Ini untuk orang yang menyukai kelembutan sekaligus keindahan. [...] Anda tahu, cappucino ini kopi paling genit.

Berbeda dengan café latte, walaupun penampilannya cukup mirip. Untuk cappuccino dibutuhkan standar penampilan yang tinggi, mereka tak boleh kelihatan sembarangan. Kalau bisa, terlihat seindah mungkin (Dee, 2012: 4).

Kutipan diatas membahas
tentang jenis kopi cappucino. Cappucino sebagai bentuk A message yaitu bentuk informasi yang berwujud salah satu jenis kopi olahan yang memiliki busa di permukaannya. Makna tersebut merupakan makna denotasi atau makna lumrah, namun selanjutnya juga dijelaskan bentuk makna kedua atau makna terseirat. Bentuk dari cappucino ini 
memberikan sebuah implementasi tentang karakteristik bagi orang yang meminumnya yaitu kelembutan dan keindahan yang terlihat dari bentuk kopi tersebut. Hal tersebut juga belaku bagi jenis kopi kedua yang disebutkan yaitu cafe latte yang dianggap memiliki standar karakteristik di bawah dari cappuccino.

Selanjutnya juga dingkapkan satu jenis kopi lagi yaitu kopi tubruk.

"Lugu, sederhana, tapi sangat memikat bila kita mengenalnya lebih dalam," Ben menjawab cepat "Kopi tubruk tidak peduli penampilan, kasar, membuatnya pun sangat cepat.[...]. Tapi, tunggu sampai Anda mencium Aromanya(Dee, 2012: 5).

Kopi tubruk telah memiliki definisi sendiri yang tersirat dalam kutipan tersebut, dari makna sebenarnya dan makna yang mengimplikasikan bentuk karakteristik. Makna lain dapat diambil dari kopi tubruk. Kopi ini berasal dari Indonesia segala sifat dan karakter yang ada menjadi cermi dari Indonesia, dari pandangan sebuah Negara dan penduduknya. Kopi tubruk ini mewakili Indonesia sebagai bentuk pertahanan diri dari kedua jenis ko[pi yang telah disinggung yang berasal dari luar negeri. Kopi tubruk adalah bentuk pandangan ketimuran atau bentuk pandangan tradisional yang sejajar dengan kopi dari luar negeri sebagai bentuk modernitas ataupun sosok barat.

A model, diartiakan sebagai sebuah bahasa, yakni sistem abstrak, yang umum bagi pengirim dan penerima, yang memungkinkan tindak komunikasi terjadi. Filosofi Kopi dipandang sebagai a model dilihat dari bentuk dialog yang ada didalamnya yang menghubungkan tokoh satu dengan lainnya. Pandangan lainnya yang dapat dilihat adalah hubungan atau dialog antara teks Filosofi Kopi dengan pembacanya. Hal ini ditegaskan dengan pernyataan Lotman (1990:63)

A text and its readership are in a relationship of mutual activation: a text strives to make its readers conform to itself, to force on them its own system of codes, and the readers respond in the same way. The text as it were contains an images of its "own" text, bahwa sebuah teks (dalam hal ini sastra menjalin hubungan dengan pembacanya dalam aktivasi mutual (masing-masing saling menghidupkan).

Dalam konteks struktur naratif yang dikatakan Lotman, terdapat tiga hal utama yaitu ruang artistik, plot, dan persona. Ruang artistik adalah medan semantis yang berupa elemen-elemen yang saling berhubungan satu sama lain dalam bentuk oposisi berpasangan, baik secara vertikal maupun horizontal. Plot adalah serangkaian peristiwa yang saling berhubungan satu sama lain dalam kerangka usaha penerobosan terhadap medan-medan semantik yang membangun struktur ruang artistik di atas. Persona adalah representasi fungsi-fungsi abstrak, baik fungsi agen yang menjadi penerobos medanmedan semantik, maupun perintang yang mencoba mempertahankannya (Faruk, 2002:27).

Artistik, dalam cerpen ini terdapat dua setting tempat secara global, kota dan desa. Kedua ini membentuk suatu oposisi yang akan mencerminkan pandangan modern dan tradisional. Selanjutnya akan dispesifikkan dengan oposisi kafe dan warung. Kafe menjadi simbol kota 
tempat kediaman Ben dan Jody dan warung merupakan simbol dari desa tempat pak Seno tinggal. Kedua hal ini membawahi dari desa dan kota yang akan mengkerucut lagi dalam bentuk oposisi cappucino dan café latte yang beroposisi dengan kopi tiwus yang berbentuk kopi tubruk. Oposisi-oposisi ini mengemban pandangan yang sama yang akan membawa ke ranah selanjutnya yaitu semiosphere.

Plot, dari cerpen ini adalah sebagai berikut.

1. Pengenalan tokoh utama Ben dan Jodi serta latar belakang kemunculan kedai kopi yang selanjutnya dibei nama Filosofi Kopi.

2. Keberadaan kedai ini memicu kedatangan berbagai khalayak dari orang iseng, penikmat kopi, hingga orang-orang kelas atas yang memberikan tantangan kepada Ben.

3. Ben menerima tantangan dan mendapatkan hadiah tantangan tersebut, hingga terciptalah Ben' Perfecto.

4. Bens's Perfecto ini memicu kehadiran bapak penyuka kopi yang akan merujuk pada konflik utama.

5. Bapak tersebut mengatakan tentang keberadaan kopi yang lebih enak dari Ben's Perfecto yang memicu Ben untuk mencari keberadaan kopi tersebut.

6. Ben menemukan warung pak Seno di sebuah desa yang membawanya kepada kopi tiwus.

7. Kopi tiwus yang memberikan gejolak naik-turun pada Ben yang akhirnya ben memutusnkan untuk mengurungkan niat untuk pension karena merasa malu pada kesombongannya.

Persona, dapat dipandang sebagai agen, tokoh, atau pelaku. Ben dan Jodi keduanya adalah tokoh sentral yang pada awal dapat berjalan seirama. Namun keduanya memiliki wacana yang oposisional. Ben adalah seorang yang idealis memandangs egalanya dengans ebuah prinsi dan Jodi cenderung melihat dalam segi materialis yang melihat angka-angka dan profit. Selanjutnya adalah pria perlente dan pria setengah baya keduanya memiliki pandangan yang berlawanan. kesuksesan menjadi patokan pria perlente tersebut bahkan kopi menjadi objek untuk memberikan legitimasi materi yang ia miliki, pandangan hidup darinya pun berwujud hal yang materialistis yaitu kesuksesan yang dilihat dari uang. Sedangkan, pria setengah baya lebih memilih bahwa tingkat paling tinggi dari hidup adalah kenyamanan. Bagi bapa setengah baya tersebut kopi menjadi rutinitasnya setiap hari yang mengimplementasikan bahwa adanya kerutinan dilandasi dari rasa nyaman.

Ben dan pak Seno, kedua tokoh ini menjadi kunci perdebatan yang selanjutnya didamaikan oleh Jody. Kopi menjdai objek bagi Ben dan Pak Seno. Ben muncul dengan keidealismenan tentang kopi dengan berbagai konsep serta ilmu yang ia peroleh dari luar negeri dan sekali lagi wacana barat atau luar negeri muncul dari Ben. Ben bahkan melihat kopi dari sisi materi juga dengan dibuktikan harga ben's perfecto yang jauh lebih mahal. Pak seno adalah seorang yang apa adanya, melihat kopi hanya sebagai kopi, pak Seno melihat kopi dari rasa dari maknanya yang diperoleh ketika diminum bukan dari perkara uang, bahkan pak Seno tidak mematok harga untuk kopinya. Pak Seno melihat dalam sudut pandang yang lebih filosofis bentuk idealisme lain yang berbeda dengan Ben.

Semiosphere adalah unit semiosis yang merupakan mekanisme fungsional yang paling kecil, bukan 
sesuatu yang terisolasi, melainkan seluruh ruang semiosis budaya yang selalu dipertanyakan. Mengidentifikasi bagian ini sama halnya mencari kesinambungan dengan analisi sebelumnya terkait dengan teks cerpen tersebut. Wacana yang jelas terlihat adalah modernitas dan tradisionalitas yang dioposisikan. Moderinitas yang dianggap sebagai bentuk mutakhir, hebat, unggul, dan sebagainya ternyata mampu diimbangi dengan wacana kopi tubruk. Kopi tubruk adalah anak tangga yang menyelaraskan keduanya. Namun, keberadaan kopi tiwus yang mengalah kan Ben's Perfecto menjadikan wacana ini terjungkal, tradisionalitas memperoleh

kemenangannya. Tradisionalitas menjadi wacana yang lebih nasionalis karena berasal dari negeri sendiri. Negeri sendiri memperoleh kemenangannya yang dicerminkan dari plot cerita cerpen yang berujung pada kemenangan kopi tiwus. Pada akhirnya wacana kopi yang dilihat dari modernitas, materi dan segalanya runtuh dengan keluguan yang mencerminkan sebuah budaya. Sebuah budaya tradisional dari racikan secangkir kopi tiwus, lugu, sederhana, yang melihat hidup apa adanya.

Pandangan lain yang dapat dikaitkan adalah tentang kapitalisme, bagaimana komoditas kopi menjadi sebuah hal yang materialistik sekali.modern akan selalu berjalan beriringan dengan kapitalisme, semuanya akan di ukur melalui uang seperti Ben's Perfecto. Sedangkan tradisionalitas adalah hal yang akan selalu "merakyat" seperti kopi Tiwus milik pak Seno. Kemenangan kopi Tiwus ini memberikan wacana bahwa ada hal yang lebih bermakna dari sekedar materi, rasa dan sebuah makna hal yang jauh lebih menentramkan yang tak bisa dig anti oleh materi apapun. Hingga akhirnya materi yang dianggap sebagai puncak kemenangan hanya akan teronggok tak tersentuh siapapun.

\section{Tanda Budaya dalam Sisi Eksternal Cerpen: Relevansi di Masa Sekarang.}

Cerpen Filosofi Kopi muncul di era tahun 90an, namun tidak begitu terlihat kehadirannya. Tema tentang kopi bukan sebuah hal yang menonjol kala itu. Namun pada tahun-tahun 2014 karya ini mampu booming kembali. Kumpulan cerpen tersebut kembali di cetak ulang, bahkan hingga dijadikan sebuah film.

Mengapa hal tersebut dapat terjadi? Hal tersebut perlu dipikirkan baik-baik. Dewasa ini kopi menjadi hal yang sangat bergengsi, kafe-kafe yang mengusung berbagai jenis kopi di seluruh dunia mulai bermunculan di kota-kota, pinggir, jalan, hingga ganggang pedesaan. Kopi menjadi sebuah primadona. Melihat konteks lingkungan yang seperti inilah beberapa orang melirik kembali Filosofi Kopi dan orang-orang tersebut adalah para kapitalis. Filosofi kembali dihidupkan dengan kesesuaian lingkungan, semua semata-mata dikarenakan materi. Pencetakan ulang kembali, sedikit bnyak juga dikarenakan materi, hingga dibuatkan sebuah film yang menceritakan tentang kisah tersebut. Film ini adalah produk kapitalis yang memanfaat kan sastra untuk memperoleh materi. Pada akhirnya kemunculan kembali serta boomingnya filosofi kopi adalah bentuk rekayasa dari para kapitalis untuk mencari inovasi berburu materi.

\section{PENUTUP}

$$
\text { Filosofi Kopi dalam }
$$
penulisannya mampu memunculkan beberapa oposisi binner yang memicu 
bentuk semiosphere. Bebeapa wacana budaya seperti tradisionalitas dan modernitas, hingga wacana barat dan timur, dan berujung pada bentuk kapitalisme. Filosofi Kopi hadir dengan oposisi yang sangat pas sehingga penggambaran bentuk budaya juga dapat terlihat sesuai dengan teori Lotman. Lotman beranggapan bahwa budaya adalah teks yang sangat luas, melalui penggambaran budaya-budaya tersebut sebagai sebuah konteks terciptalah penggambaran cerpen Filosofi Kopi yang mampu memberikan makna bagi para pembacanya.

Ulasan diatas merupakan ulasan terkait dalam sisi "dalam "cerpen. Terdapat beberapa hal yang bisa ditarik relevansi dengan zaman sekarang. Faktanya cerpen tersebut

\section{DAFTAR PUSTAKA}

Lotman, M. Jurij. 1977. The structure of The Artistic Text. Translated by Ronald Vroon. Michigan: Ann Arbor. 1990. Universe of The Mind. A Semiotic Theory of Culture. London, New York: LB. Tauris \& Co. Ltd.

Faruk. 2002. Novel Indonesia, Kolonialisme, dan Ideologi Emansipatoris. Yogyakarta: Ombak.

Hoed, H. Benny. 2011. Semiotik dan Dinamika Sosial Budaya. Jakarta: Komunitas Bambu.

Siegers, Rien T. 2000. The Evaluation of Literary Teks (Evaluasi Teks Sastra). diterjemahkan oleh Suminto A. Sayuti. Yogyakarta: Adicita Dee. lebih relevan pada beberapa tahun belakangan ini dibandingkan pada tahun pembuatannya. Kepopulerannya pun juga tengan naik di beberapa tahun terakhir.hingga pada akhirnya cerpen tersebut menjadi sebuah objek kapitalisme baru. Walaupun penggambaran dalam novel menolak hal tersebut, namun secara eksternal cerpen ini menjadi sebuah objek yang mampu menghimpun materi sehingga diberdayagunakan oleh para kapitalis. Hal ini dapat menjadi sebuah nilai posistif ataupun negative, kapitalisme tersebut faktanya juga mengusung pada bentuk seni yang lain yang mampu memberikan interpretasi secara lebih luas. Hingga pada akhirnya yang mampu menilai adalah pembaca itu sendiri, bagaimana ingin menilai dan menyikapi. 